\section{SCIENCE IN SOUTH-WEST CHINA}

\section{THE BIOLOGICAL AND SOCIAL SCIENCES}

By DR. JOSEPH NEEDHAM, F.R.S.

British Council Cultural Scientific Mission in China

$I^{\mathrm{N}}$ the previous article (July 3, p. 9) some account was given of the work being done in the physicochemical sciences by our Chinese colleagues under the difficult conditions in this part of Free China.

Exactly how difficult the conditions are is not easy to describe. The students live in badly overcrowded dormitories, and are severely subject to disease such as tuberculosis. Affections such as trachoma, caused by inadequate washing facilities, etc., are common. But the contrast between the life of the normal scientific worker as lived previously and as lived to-day is even more pronounced. Scientific men and women of great attainments are accommodated in rickety old structures around courtyards that cannot be kept clean. The scale of pay has risen only seven times while the cost of living in Yunnan has risen 103 times. I can only compare it with going to live in sheilings on the coast of Argyllshire on less than $£ 70$ a year after having held a post at $£ 1,000$ a year with a good flat. It is often hard for men whose names are well known in Europe and America to get enough to eat. How many of us would have been willing to live in such exile rather than under the invader's domination in comparative comfort?

\section{National Southwestern United University}

I turn now to some of the biological work pro. ceeding in and around Kunming. First, in the National Southwestern United University there is a good deal of botany going on under Prof. Ch'ang Ching-Yueh. Cytology is represented by Dr. Wu Su-Hsuen (she was trained at Ann Arbor, Michigan), and plant physiology by Dr. Li Chi-Tong, who is making interesting studies on the cleistogamy of the violet plant. There is a nutritional laboratory under the energetic Dr. Shen Tung, where a new and exceedingly rich source of vitamin $\mathrm{C}$ has just been discovered-perhaps the richest known-Emblica officinalis ("i-gan"), often described as the Chinese olive, but really belonging to the Euphorbiaceæ. In entomology, under Lin Chung-Lo and Lu Chin-Rjêng, much work is going on on the lac insect, an animal of much economic importance to China. Similarly, a complete key to the caterpillars of Yunnan is nearly ready, with special reference to the pests. A complete key to the Yunnan flora, mostly the work of the late Prof. Wu Yuen-Chen, who died last year from hardships encountered here and from inadequate hospital equipment, is now being prepared for the press by Dr. Chien Cho-Po.

\section{Chinghua Institutes of General Physiology and Plant Pathology}

Out at Dragon King Pool there are the Chinghua Institutes of General Physiology and Plant Pathology, The former is under the leadership of Dr. T'ang P'eiSung, very well known in America, especially at Chicago and Woods Hole, as a collaborator of Dr. R. W. Gerard. Dr. T'ang's flair for originality and ability in younger men has gathered round him, besides Shen Tung, such men as Dr. Yin Hung-Chang, an expert on plant growth hormones from the California Institute of Technology, and Dr. Lou Ch'ông-Hou, a biophysicist who is studying electric responses of plants. It was a remarkable thing to see a complete laboratory for the assay of plant growth substances in these primitive conditions. Dr. T'ang's group is also interested in the mechanims of subterranean fruiting in the peanut, Arachis hypogeum, a subject again of economic importance for China. They have made an extensive series of studies, too, on the metabolism and physiology of the silkworm, on the streaming of plant protoplasm, and on the production of polyploids. Stimulated by the practical problems confronting Chinese science, Dr. T'ang has written a book of essays, which it is hoped may be published either in England or America.

The other Chinghua Institute, that of Plant Pathology, is presided over by Dr. Tai Fang-Lan. Here all kinds of interesting things also are going on. Taxonomy of mushrooms (Chiu Wei-Fan) ; nematode carriers of wheat blight ( $\mathrm{Yu} \mathrm{Ta}-\mathrm{Fu}$ ); genetics of resistance to bean wilt and wheat rust (Fang Chung. Ta); morphology of aquatic fungi (Shen ShanChong); and an extraordinary system of symbiosis or cross-stimulus between certain termites and a certain fungus (Chou Chia-Chih).

The number of papers in manuscript which this Institute and others have accumulated in the past two years is considerable. The fact that scientific papers cannot be adequately printed in China, and the fact that the ordinary mails, owing to censorship and other difficulties, are not such as to encourage scientific men to entrust their manuscripts to them, constitute a menace to the morale of our Chinese colleagues. It is therefore the policy of the British Scientific Mission to facilitate the passage of meritorious papers to Britain and America, for publication in our own scientific journals, until those of China can be got on their feet again.

\section{Drug Research Institute}

Not far from the Chinghua institutes, in the same part of the country, is the Drug Research Institute of the Ministry of Education, directed by Dr. Ch'ing Li-Pin. Here special attention is devoted to the botany and pharmaceutics of the indigenous Chinese drugs. This Institute is housed in an old village Buddhist temple, in the main hall of which a gigantic Kuan-Yin image looks down approvingly at the indexed collections of dried plants, the numerous editions of the "Pên Tsao" (the classical Chinese pharmacopoia), and the small printing-press on which a bulletin containing descriptions of new plant species is prepared, and some numbers of which have already been sent to Kew.

Dr. Ch'ing Li-Pin is also the director of the physiological section of the Peiping Academy, together with the zoological section (director, Dr. Chang Hsi), on the shores of the great lake in the Kunming plain. The latter possesses a good working library. Investigations on the plankton of the lake are proceeding (Liu Yung-Pin), on the diseases of the edible fishes of the lake, and on the molluse Margaria, an edible viviparous gastropod which is very abundant in this region.

\section{National Epidemics Prevention Bureau}

In another part of the Kunming area is the National Epidemics Prevention Bureau, under the directorship of one of China's most able bacteriologists, Dr. T'ang Fei-Fôn, assisted by Dr. Wang Yo-Wei and a large staff. Here last year five million doses of typhoid inoculation were produced. The Institute 
also makes smallpox lymph, diphtheria and tetanus toxoid, and a good many other things, including diagnostic antigens such as the Widal test serum for typhus, and the Kahn antigen for syphilis. Preparations are under way for producing typhus vaccine. Dr. T'ang is well known to bacteriologists, immunologists and tropical disease specialists in England and America. His plant maintains high standards of cleanliness in the stables and animal houses in spite of the lack of any running water supply, and an extremely efficient system in the growing, bottling and testing departments. Particularly interesting is the fact that the plant includes a complete glass factory, where neutral glass is made from the proximate ingredients and worked into ampoules and capillaries. The glassworks also produce flasks of all shapes; tubing, condensers, beakers, etc. The story of the plant is an epic in itself. For many months the only available boiler was one. which was leaky and unsafe, requiring repairs every evening after use, and with this all the sterilizing apparatus, distilled water supply, etc., had to be run ; fortunately no accident took place. Typical of the Institute's pertinacity is the re-utilization of agar by a method specially devised. Dialysis took place from a raft in the lake until the depredations of fishes became too great, and a dialysis tank had to be rigged up on land out of the very few materials available. When commercial supplies of proteolytic enzymes ran out, a hog colony was started, and when the condition of the beasts became such as to yield but poor pepsin, the hogs were fattened by special feeding. This, however, is extremely costly, as indeed is the feeding of all the animals, which has reduced the number of horses, for example, considerably. The Institute is now supplying sera for other United Nations troops as well as Chinese, in the East.

\section{National Provincial University of Yunnan}

Within the city of Kunming itself is the National Provincial University of Yunnan, occupying a beautiful site and some of the antique buildings of the old Imperial Examination Halls. It has suffered heavily by bombing, having lost its whole chemistry building. Most of the staff are French-speaking, owing to the former French cultural influence in Yunnan. Thus Prof. Chao Yin-Lai, the organic chemist, is a former collaborator of Prof. Grignard. The courses in the medical school, small but neat, are still all in French. The president, Dr. Hsiung Ch'ing-Lai, is an able mathematician, also French-speaking. Among the heads of departments, however, is Mrs. Tsui Chi-Lan, a morphologist who had her training in Germany. She is now occupied with detailed anatomical studies on the origin of the olfactory organs in Amphibia, preliminary to experimental work on the same subject. She is a pupil of Kraus, Spemann and Hartmann.

The University of Yunnan is at present quite strong in the social sciences, having on its staff Dr. Wang Kan-Yu (a pupil of Prof. Ernest Barker) and especially Dr. Fei Hsia,o-Tung, widely known as one of Prof. B. Malinowski's most brilliant students, and for his book on village life in China. Dr. Fei's institute is the Yunnan-Yenching Institute of Sociological and Anthropological Research. It is situated in a small town some hours away from Kunming, occupying rather unusual quarters, namely, a fine old tower or pagoda, dedicated to K'uei-Ko (the god of literature), and placed there because one of the townspeople long ago attained to the dignity of being a Hanlin scholar.
The top floor, which contains the image of the god, houses part of the library, and the floor below is the main working-room. The Institute has recently published a number of valuable monographs. Dr. Hsu Lang-Kuang, Dr. Fei's chief colleague, has written on the introduction of modern medicine into a primitive community on the western borders of China, a study which necessitated close observation by him of a cholera epidemic. Like old Nicholas Culpepper in Kipling's story, "A Doctor of Medicine", it seems that the people carry out a number of hygienic measures for quite wrong theoretical reasons, but at the same time have recourse to Taoist and other magic. Other colleagues have written on labour conditions in Yunnan, and on the different types of rural economy in the province.

\section{Chinghua Institute of Statistics and Census Research}

In a different part of the same town, there is another of the Chinghua institutes, that of Statistics and Census Research. Headed by Dr. Chen Ta, ably assisted by Dr. Tai Shih-Kuang, this institute carries out experimental censuses of selected regions, observing the reactions of the peasants, checking up on various sources of error, and seeing how best to accustom the Chinese country people to a process which must in due course take place. The Institute is housed in a Confucian temple. An imposing succession of 'pailous' and gates leads into the main court, with its raised platform shaded by a few tall old pine-trees. Within the shrine, in true Confucian puritanism, there is only the golden tablet of the sage, surrounded by those of his disciples, among which those of Mencius and Chu Hsi can be distinguished. Below are the calculating machines and card indexes of the statisticians. It is felt that Confucius would be very pleased to see his house so used in the service of the teeming people of whom he said "First feed them, then educate them".

Confucius, like so many of us to-day, was concerned with problems of government. The proper relation of science to government is a problem which has scarcely yet been solved in Britain or America, still less, therefore, has it been solved in China. At a first glance, it seems that in China there is not yet a sufficiently intimate relation between the university men of science and the growing industries. There is also perhaps a tendency to over-emphasize applied science in the short-term sense at the expense of pure science, especially in the training of students and the sending of them abroad. The scientific man is ordinarily ignored or treated as academic and unpractical ; but on occasions is expected to produce practical results without delay by those who have turned a deaf ear to his requests for adequate material support and essential research supplies. The advantage of his advice within the Government organizations themselves is also not fully appreciated.

In these two articles it has been impossible to do more than run over some of the salient features of Chinese science in the far south-west. The main impression which remains with the visitor to the scientific institutions of this vitally important pro. vince is of the quite indomitable perseverance and courage which the Chinese scientific workers have shown in carrying on in the remote parts of their country, and of the extraordinary cheerfulness and even gaiety which they show in the midst of their adversity. 